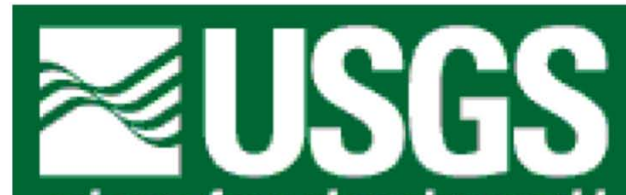

scienee for a changing world

\title{
Application of GPS Drifters to Track Hawaiian Coral Spawning
}

Open-File Report 2004-1309

Version 1.0

2004

By Gerald A. Hatcher ${ }^{1}$, Thomas E. Reiss ${ }^{2}$ and Curt D. Storlazzi ${ }^{1}$

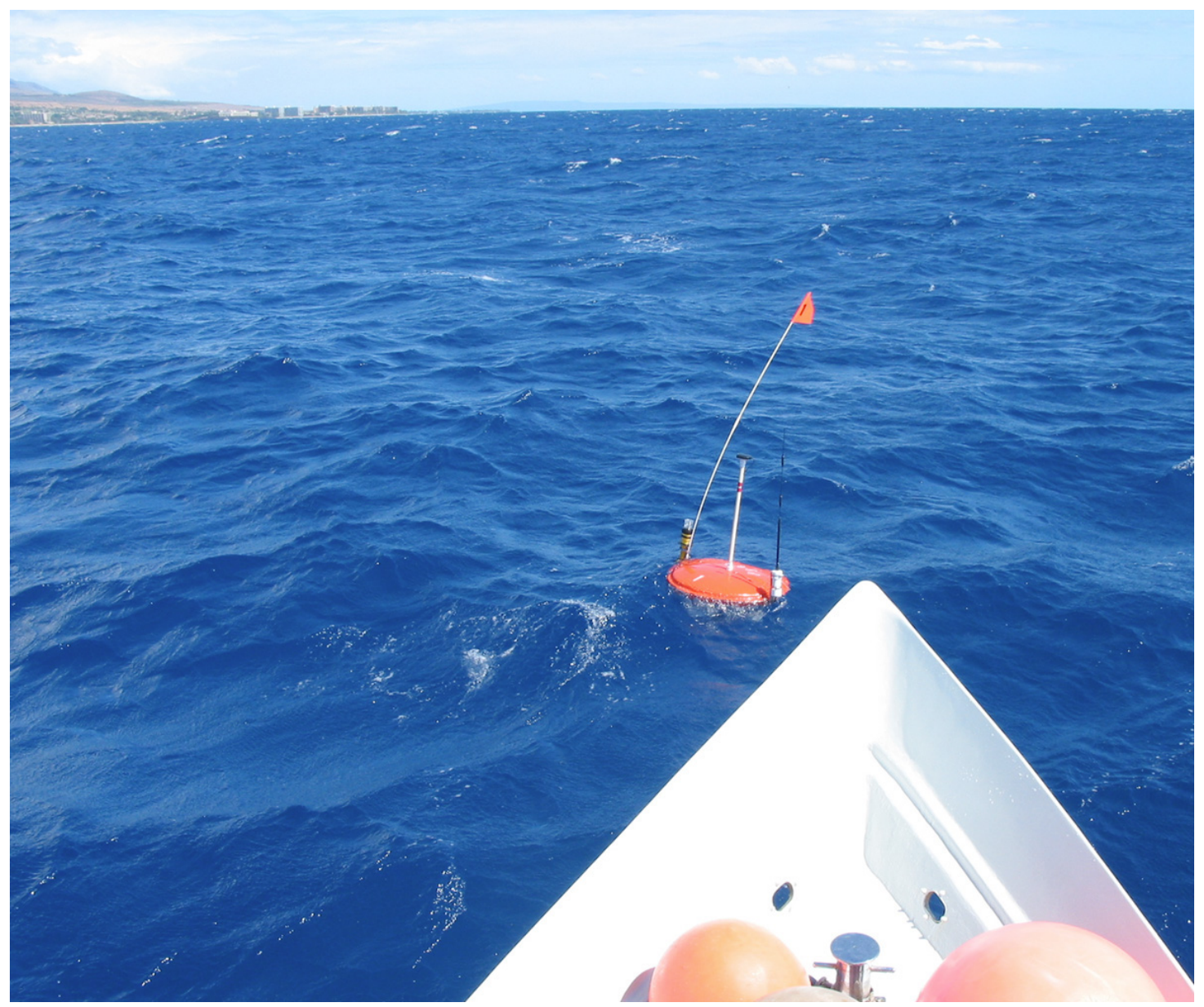

${ }^{1}$ US Geological Survey, Pacific Science Center, Santa Cruz, Calif.

${ }^{2}$ US Geological Survey, Western Region Headquarters, Menlo Park, Calif.

U.S. Department of the Interior

U.S. Geological Survey 


\section{LIST OF FIGURES}

FIGURE 1. Map of the study area location in relation to the main Hawaiian Island chain.

FIGURE 2. Photographs of drifters.

FIGURE 3. Radio repeater network and coverage area.

FIGURE 4. Drifter micro-controller circuit board part locations.

FIGURE 5. Internal components of drifter surface float.

FIGURE 6. Tidal stages during the periods of drifter releases.

FIGURE 7. A representative track plot of two drifters released near West Maui, Hawaii.

\section{LIST OF APPENDICES}

APPENDIX 1. Micro Controller Bill of Materials

APPENDIX 2. Power Budget Calculations

\section{ADDITIONAL DIGITAL INFORMATION}

For additional information on the instrument deployments, please see: http://walrus.wr.usgs.gov/infobank/a/a403hw/html/a-4-03-hw.meta.html

For an online PDF version of this report, please see:

http://pubs.usgs.gov/of/2004/1309/

For more information on the U.S. Geological Survey Western Region's Coastal and Marine Geology Team, please see:

http://walrus.wr.usgs.gov/

For more information on the U.S. Geological Survey's Coral Reef Project, please see:

http://coralreefs.wr.usgs.gov/

\section{DIRECT CONTACT INFORMATION}

General Project Information

Dr. Michael E. Field (Project Chief): mfield@usgs.gov

Regarding this Report:

Gerald Hatcher:

ghatcher@usgs.gov 


\section{REPORT REFERENCE}

Hatcher, G.A., Reiss, T.A. and Storlazzi, C.D., 2004. "Application of GPS Drifters to Track Hawaiian Coral Spawning." U.S. Geological Survey Open-File Report 2004-1309 14 p.

\section{INTRODUCTION}

From June 30 to July 3, 2003, scientists from the U.S. Geological Survey's (USGS) Coral Reef Project conducted an experiment to investigate one possible cause of large variations in the amount of new reef production in adjacent areas around West Maui, Hawaii. The goal was to determine whether the areas of poor growth were simply not getting enough new coral larvae recruits because of local coastal-circulation characteristics. The experiment studied the larvae dispersion by the reef-building coral Montipora capitata, locally known as "rice coral," which simultaneously release bundles of eggs and sperm into the water column each summer shortly after the new moon during spring tides. The bundles rise to the surface, break apart, and then rely on chance encounters with the eggs and sperm from other bundles for fertilization. Once fertilized, most of the eggs settle to the bottom, generally within 2 to 4 days, and attach to hard substrate to begin the creation of a new coral colony.

\section{Project Objectives:}

To track the water containing the Montipora capitata sperm and eggs bundles as it moved during several days from its origin above a healthy reef, a system of current drifters with an integrated real-time tracking system was developed by the USGS using the following system requirements:

- An operational lifetime of at least 3 days of continuous deployment for each drifter.

- They must travel with a water mass at a specified depth.

- Deployable and recoverable by hand using a small "Boston Whaler" size boat.

- Collect position data at a sufficient rate to determine unambiguously if the drifter passed over a specific reef.

- Capable of being tracked (nearly) everywhere in the Pailolo Channel between Maui and Molokai and in the Auau Channel between Maui and Lanai.

- Able to be tracked remotely in real-time 24 hrs a day.

- Capable of handling as many as 10 drifters simultaneously.

\section{Study Area:}

Deployments were conducted off Western Maui, Hawaii, USA, in the Pailolo and Auau Channels between the Hawaiian Islands of Maui, Lanai, and Molokai (FIGURE 1). All vessel operations, including mobilization and demobilization, were based out of Lahaina Harbor, Maui, Hawaii. 


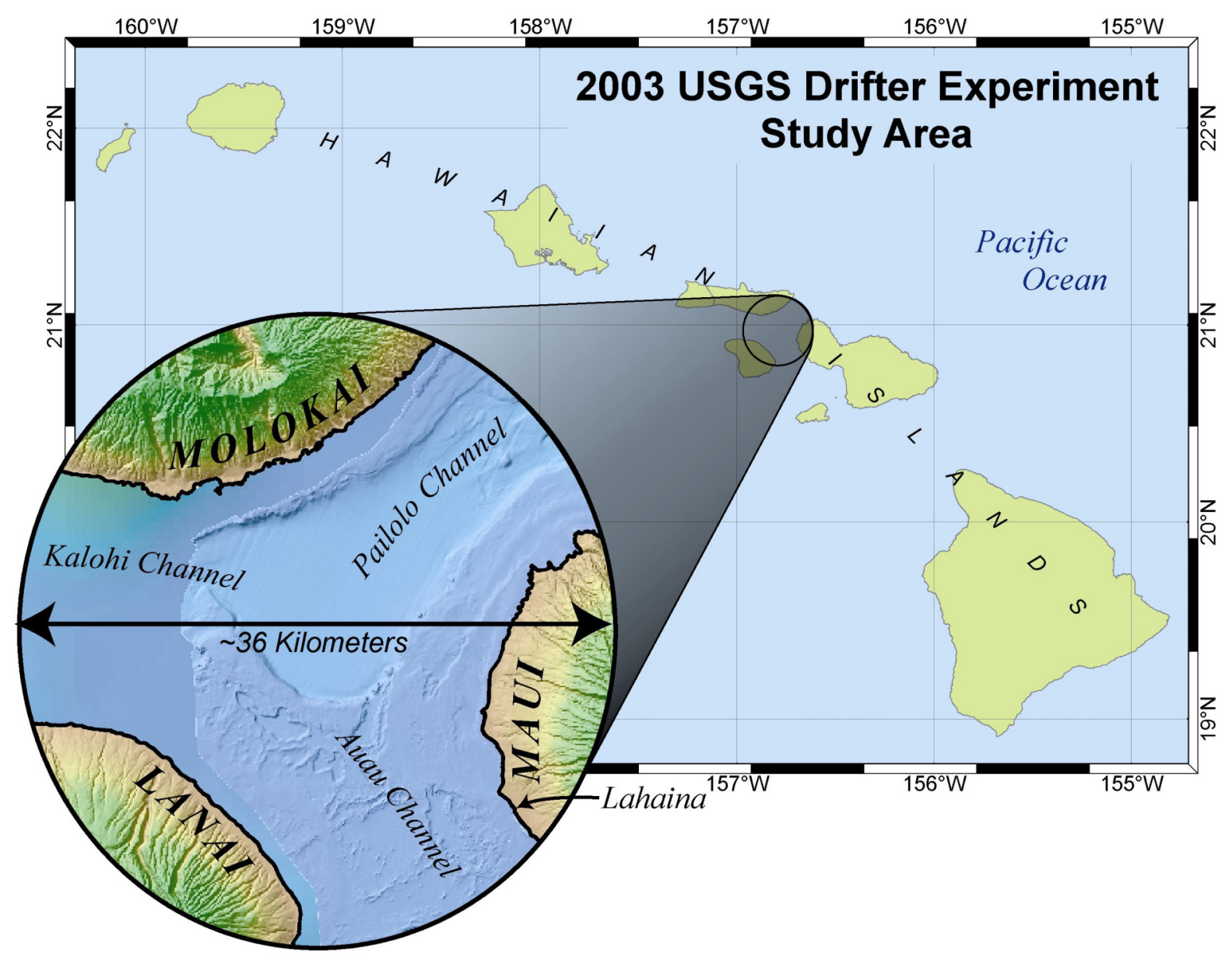

FIGURE 1. 2003 USGS Drifter experiment study area located in the Pacific Ocean waters between the Hawaiian Islands of Molokai, Maui and Lanai.

\section{OPERATIONS}

This section provides information about the personnel and equipment used during the drifter deployments. Please see APPENDIX 1 and APPENDIX 2 for additional mechanical and power consumption information.

\section{Scientific Party:}

The drifter design team consisted of Tom Reiss (Menlo Park, CA), responsible for the mechanical engineering, and Gerry Hatcher (Santa Cruz, CA), responsible for the electrical and software engineering. The USGS drifter-experiment chief scientist was Mike Field (Santa Cruz, CA) and Curt Storlazzi (Santa Cruz, CA) was lead oceanographer. Joshua Logan (Santa Cruz, CA) was drifter technician.

\section{Equipment Review:}

The drifters consisted of two $\sim 30 \mathrm{inch} / 75 \mathrm{~cm}$ concave disks put together in a clam shell fashion enclosing flotation and a waterproof box that contained the electronics. The entire drifter assembly weighed approximately $30 \mathrm{lbs} / 13.5 \mathrm{~kg}$, and was 
manageable by hand in a small boat. The drifter hardware was designed to minimize the surface exposure to wind and was attached either directly or via cable to a subsurface fin arrangement called a drogue. The intention was that the underwater drogue would tow the drifter along with the water mass in which it floated, regardless of surface wind speed or direction. This was verified during several deployments of an early version of the drifters where they were observed from shore and/or small boat to travel with the ocean currents directly up-wind (FIGURE 2). Therefore, simultaneously deploying drifters with drogues at different depths allowed for separate water masses to be tracked as they dispersed from the area of coral spawning.

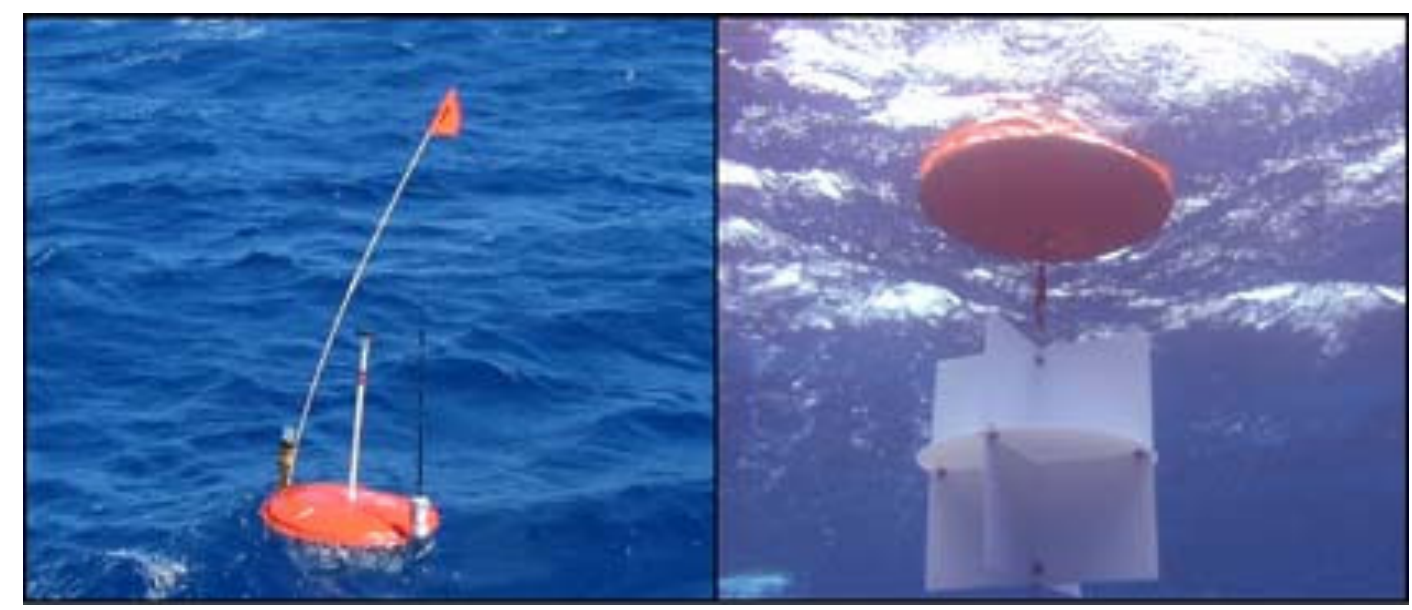

FIGURE 2. Photographs of the drifter deployed. View of a drifter from above (left) and from below (right). Photograph on right shows the underwater fin assembly or "drogue." Photographs courtesy of Brian McLaughlin (University of California, Santa Cruz) and Mike Field (USGS).

In order to record the track of the drifters with sufficient resolution each unit was outfitted with an on-board Global Positioning System (GPS) unit capable of receiving the Wide Area Augmentation System (WAAS) corrections. In the Hawaiian Islands the WAAS corrections are fairly reliable, enabling off-the-shelf GPS positional accuracies on the order of three to four meters or better. In the west Maui area ocean current velocities are usually less than 1.5 knots $(0.77$ meters/sec). Under these conditions recording a fix every 30 seconds would give a maximum horizontal distance between navigation fixes of less than 25 meters, more than adequate to meet the requirements. At a 30 second data rate, the GPS was capable of storing approximately 3.5 days of fixes internally. The on-board storage capability was a backup to the remote data logging capability described below.

Since it was impractical to visually track multiple drifters that were likely to travel many kilometers in separate directions over several days and nights, remote tracking was required. To enable this capability, $900 \mathrm{MHz}$ spread spectrum data radios were installed on each drifter. A radio network was set up to vastly increase the area within which the drifters could be tracked through installation of two repeater stations, one on the northern side of Lanai and the other on the east end of Molokai (FIGURE 3). The base station was located on the $7^{\text {th }}$ floor balcony of a hotel room that had a line-of-site 
view to both repeater stations and of the reef over which the drifters were released. Using this network configuration data could be received from the drifters if they had line of site view to either of the repeaters or directly to the base station.

\section{USGS Drifter Experiment Radio Repeater Network}

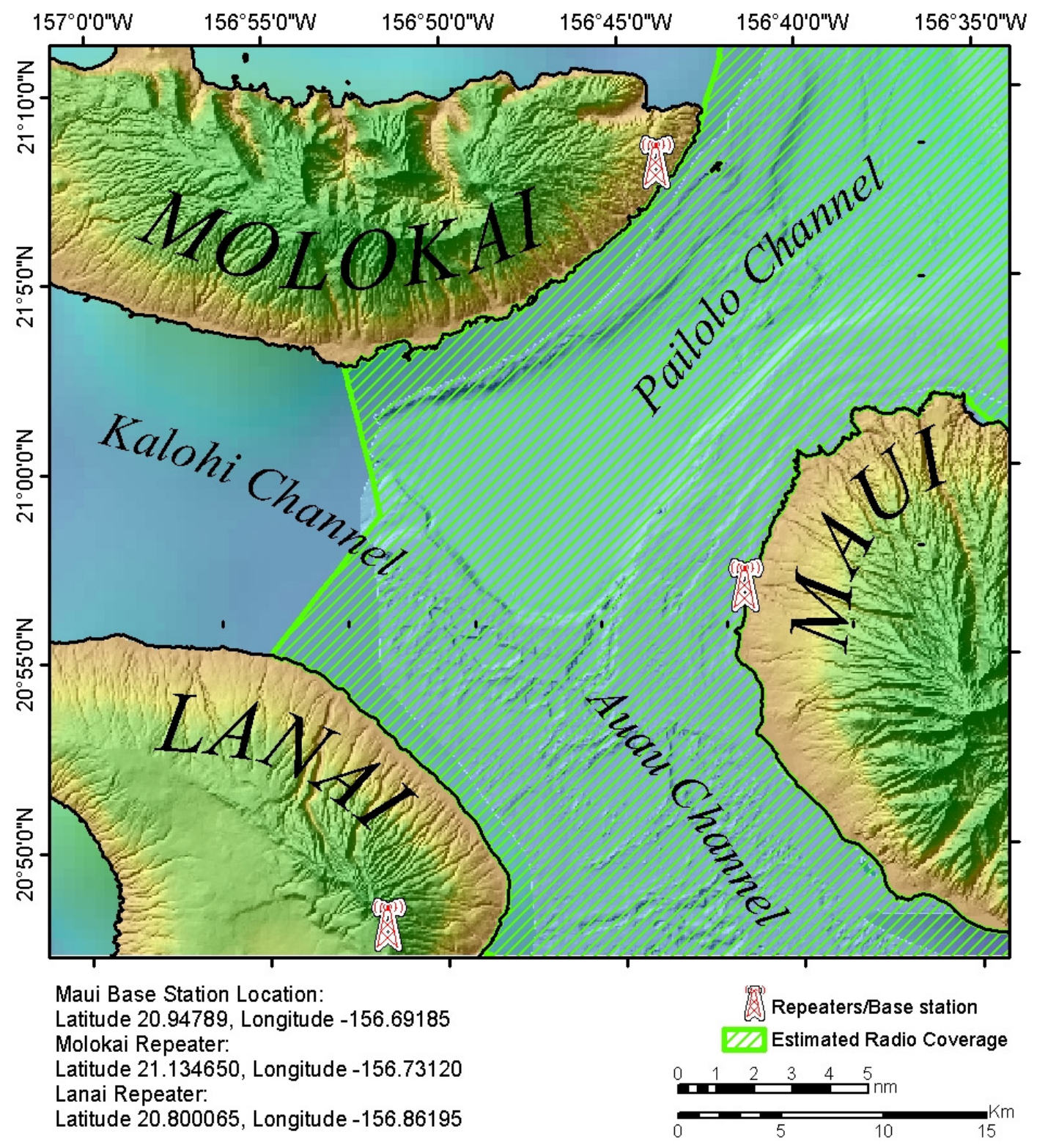

FIGURE 3. Radio repeater network and coverage area. 
Most off-the-shelf GPS devices available today, like those installed on the drifters, are capable of navigation data output through a serial data connection. The information is usually available in either a vendor specific binary format or in the standard National Marine Electronics Association (NMEA) ASCII format. The NMEA standard was developed to allow marine instruments such as GPSs, autopilots, and radars to be easily interfaced regardless of their manufacturer. NMEA data can usually be expected from any commercial GPS. Since we did not want the design to be entirely dependant on a particular GPS manufacturer, we chose the NMEA format. However, while the NMEA standard is well documented and provides all the information required of the drifters, namely time, position, speed and direction of travel, it does not provide for any type of unit ID. Since the NMEA format does not provide for an ID, if multiple drifters simultaneously transmitted straight NMEA data over the same data radio network it would be difficult to tell which drifter transmitted any particular string.

In addition, most off-the-shelf GPS units provide NMEA data at a fixed rate of once per second or once every other second. The rate is set by the manufacturer and is generally not changeable by the end user. This created several problems for the drifter design. First the transmission of data over the radio is expensive in terms of power consumption, both on the drifter and at the data repeaters. Since the experiment only required position fixes once every 30 seconds, transmitting straight from the GPS would transmit data over the radio network 29 times more often than required. Also, the GPS units sent several NMEA strings every transmission cycle, many of which contain repeated or other information not required for this experiment. Using the power consumption specifications of the data radio supplied by the manufacture, more than 13 Amp-hours ( $10 \mathrm{lbs} / 4.5 \mathrm{~kg})$ of additional battery power would be consumed transmitting unneeded information during a three-day deployment. The experiment also specified that we be able to track as many as 10 drifters simultaneously. If each of 10 drifters were transmitting straight NMEA every second, there would be a tremendous amount of radio traffic and data collisions, possibly causing significant loss of data and very poor performance. Clearly, this was not acceptable.

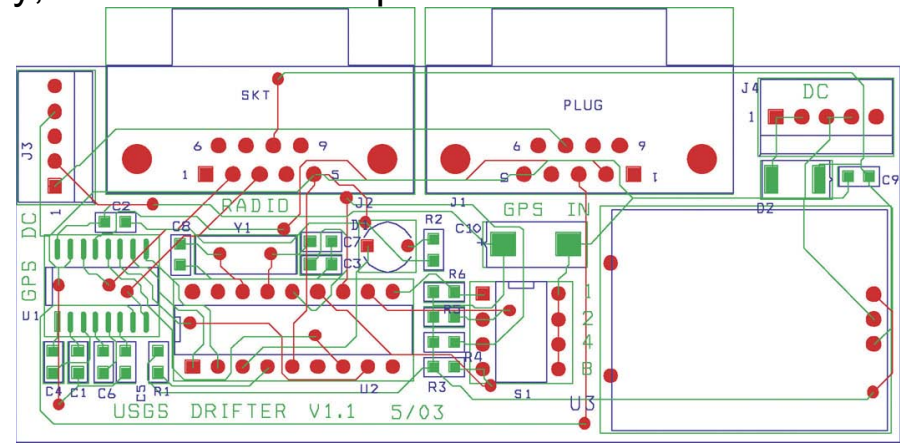

FIGURE 4. Drifter micro-controller circuit board part locations. See bill of materials list APPENDIX 1.

To overcome these difficulties a custom micro-controller circuit (FIGURE 4 \& 5 ) was engineered through a collaborative effort with Craig Okuda of the Monterey Bay Aquarium Research Institute (MBARI) at Moss Landing, California. The micro-controller was programmed to read the NMEA data provided by the GPS, remove unnecessary or redundant information and reformat the data into a custom string which included a 
unique ID for each drifter. The micro-controller then transmitted the data just once every 30 seconds. Since each GPS provides very precise time the micro-controller was also able to reduce data "collisions" on the radio network by uniquely offsetting the transmission timing of each drifter. The offset was determined from each unit's ID and created as follows, drifter\#1 transmitted at 1 and 31 seconds of every minute, drifter\#2 transmitted at 2 and 32 seconds of each minute, and so on. The individual data transmissions took much less than one second to travel the network, so this scheme provided ample spacing between transmissions.

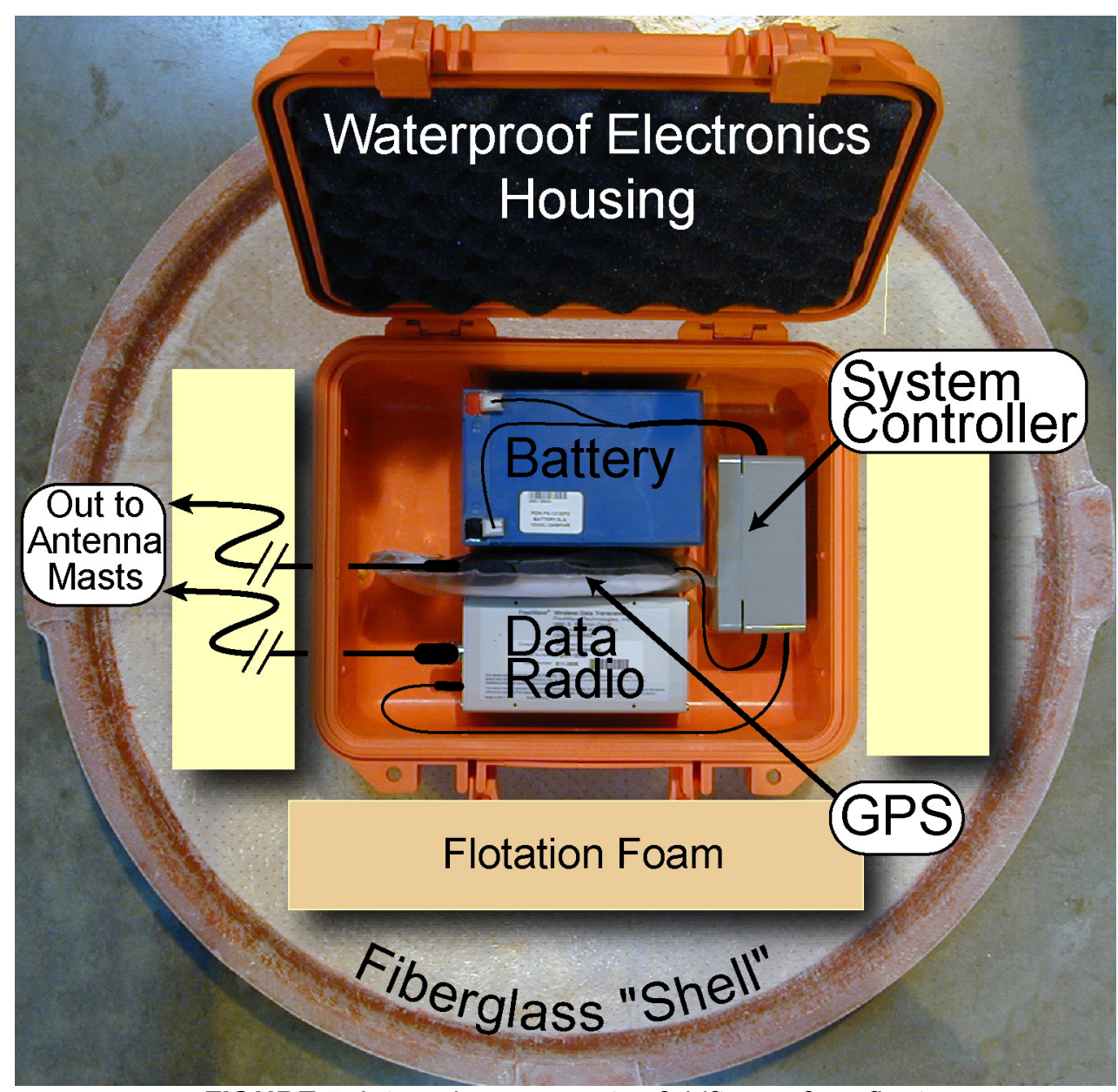

FIGURE 5. Internal components of drifter surface float.

At the base station, a laptop computer was connected to the master data radio's serial output. The serial data received by the laptop consisted of a series of navigation strings received consecutively every 30 seconds from each of the drifters that were turned on within range of the radio network. On the laptop, a program was created which received the data through the computer's serial port, logged the data to an ASCII file and then supplied the drifter data "on-demand" to any "client" programs requesting the data. This server function of the program provided the data to clients via standard computer Ethernet network and was capable of supplying multiple clients simultaneously. In this way several computer stations (if networked together) could 
monitor the real-time data simultaneously sharing the same data supplied by the single server.

To graphically track the drifters, locate the tracks in relation to other critical data (such as the shoreline), and create hardcopy plots, a commercial Geographic Information System (GIS) package was used. The GIS was customized through software to enable it to automatically retrieve the real-time data from the server program (described above) and plot icons representing the drifters on the interactive map in their correct geographic location. A rotation was also applied to the icon to indicate the direction the drifters were traveling. The icon locations and rotations were automatically updated as new data arrived from the drifters. The icons for each drifter could be individually defined with a different shape, color, and size so they could be identified at a glance. A "trail of bread crumbs" was displayed for each drifter to facilitate tracking and forecasting the progress of the drifters. The entire drifter history logged by the "server" program described above could also be displayed when desired.

The forecasting ability provided by the real-time GIS proved invaluable in recovering two of the drifters that flipped over after the drogues broke off in choppy seas. With the drifters floating upside down in the water, the radio and GPS antennas were submerged and contact with them was lost. Both drifters were several kilometers offshore and it was several hours before a retrieval boat could be taken from other operations to attempt to recover them. By using the interactive GIS display, a position estimate and direction of travel was easily determined and given to the recovery vessel via marine radio as it arrived near the scene. In both cases, the drifters were recovered. Because both of the drifters were recovered, the exact cause of failure was determined and the problem remedied.

\section{DATA ACQUISITION AND QUALITY}

Four days of data were acquired (06/30/2003 - 07/04/2003). The tidal stages for the three periods are shown in FIGURE 5 . The drifters were successfully deployed on all four attempts. The drifters with drogues at one-meter depth tended to follow the bottom contours, first to the north (passing over the reef in poor condition) then reversing course and following the contours back to the south. These northward then 
West Maui Tides: 06/30/2003 - 07/04/2003

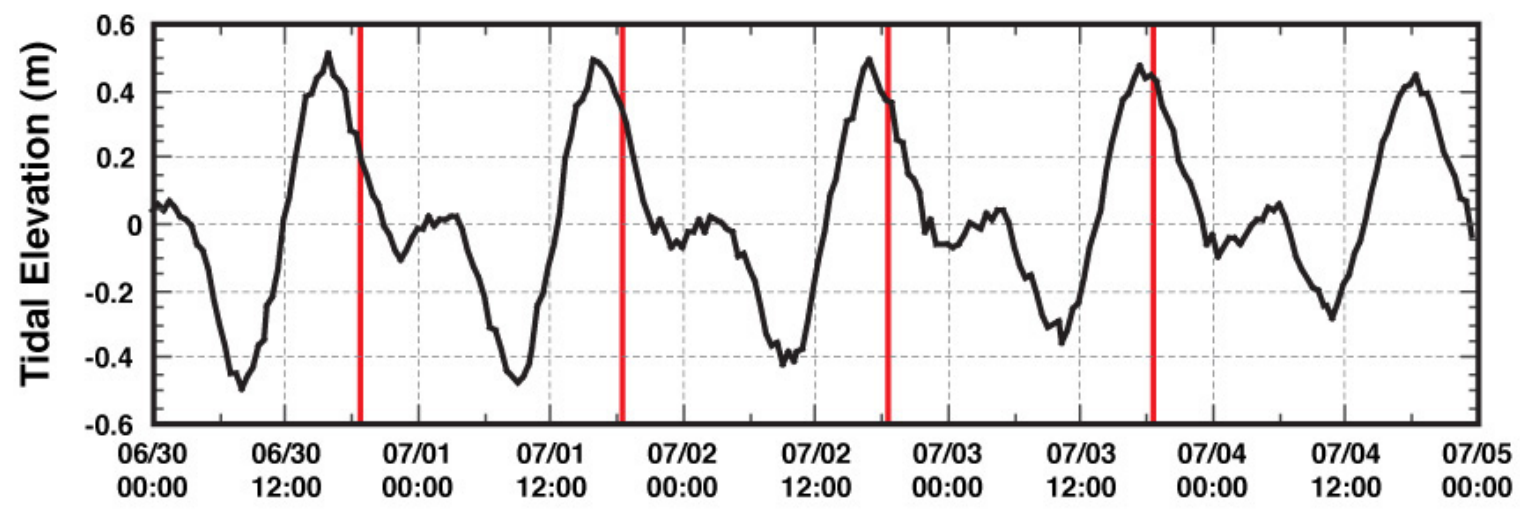

Date and Time

FIGURE 6. Tidal stages during the periods of drifter releases. Data from USGS wave/tide gauge. Dates and times are local (Hawaiian Standard Time). Red bars denote times of drifter releases.

southward tracks appeared to be driven by local tidal currents, and their speeds and directions were very similar to the currents observed over the previous 15 months by a USGS bottom-mounted, upward-looking ADCP deployed roughly four kilometers to the north of the drifters' release points (Storlazzi and Jaffe, 2003) and vessel-mounted ADCP surveys undertaken during the drifters' deployments (Storlazzi et al., 2003). The drifters gradually moved offshore during this process and into mid channel with a heading toward the island of Molokai (FIGURE 6). The drifters with the drogues attached at the surface followed similar tracks at first, but had a much stronger offshore and southerly component toward Lanai, likely due to the greater influence of wind-driven surface currents. On three occasions drifters actually crossed the Auau Channel within approximately 24 hours and landed gently on "Shipwreck Beach", inshore of the north Lanai reef flat.

The experiment indicated that the water containing coral larvae did indeed sufficiently reach the areas of degraded reef off West Maui and thus, the cause of poor live coral coverage might not be a lack of new coral larvae. Additionally, it was shown that larvae can make the inter-island crossing within the time that the larvae are still in the water column and viable. This suggests that Hawaiian reef systems are an interconnected ecosystem where effects to the reef on one island may possibly have unanticipated effects on the reefs of neighboring islands. 


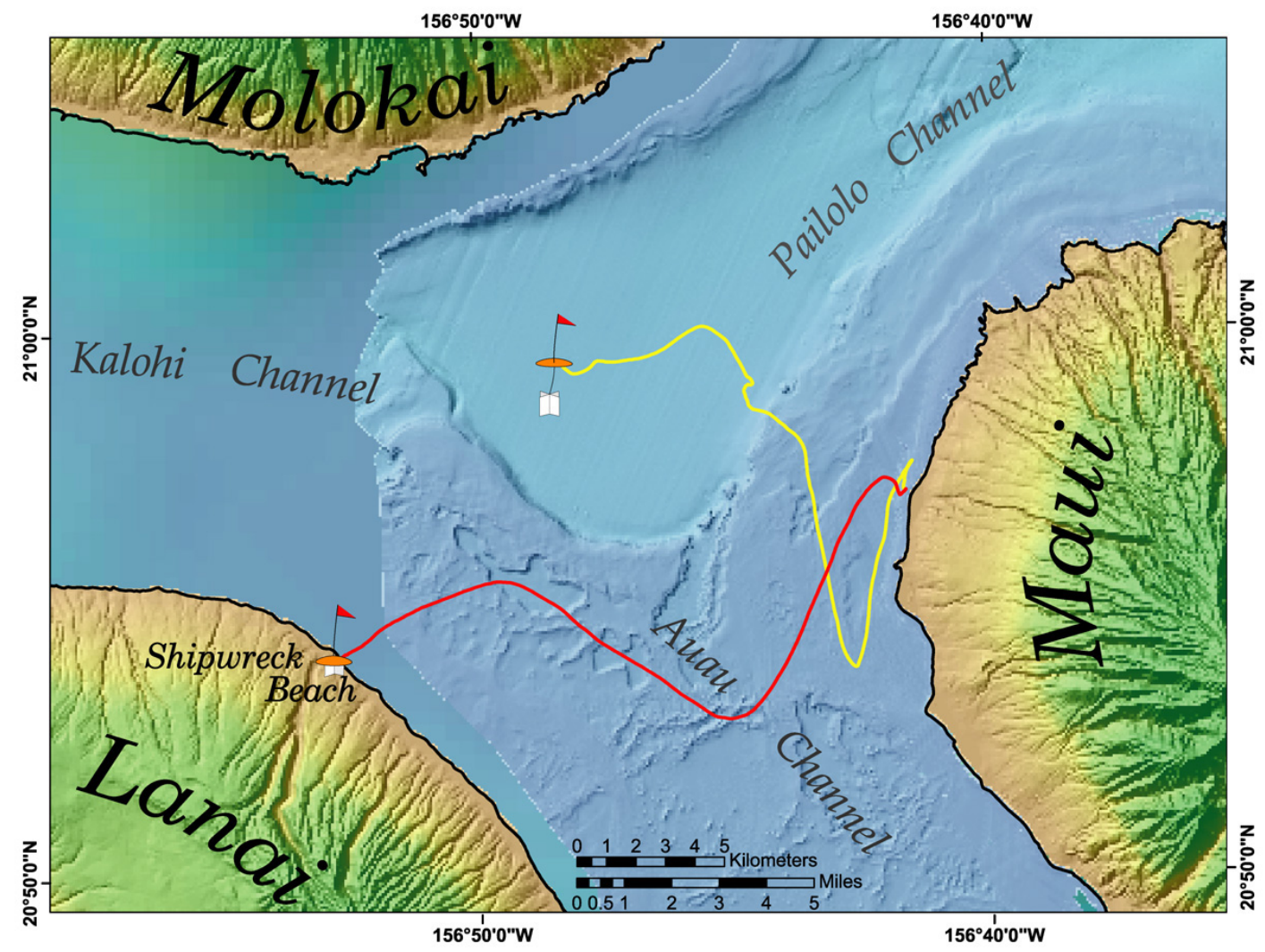

FIGURE 7. A representative track plot of two drifters released near West Maui, Hawaii. The track in red on the left is from a drifter with the drogue attached directly to the surface float. That drifter was released at 10:14 p.m. local (Hawai'i Standard) time June 30 (06/30/2003) and landed on Shipwreck Beach about21 hours later, at 7:23 p.m. July 1 (07/01/2003). The track in yellow on the right is from a drifter with the drogue at 1-m depth; it was released at 10:11 p.m. July 2 (07/02/2003) and retrieved about 39 hours later, at 1:20 p.m. July 4 (07/04/2003).

\section{FUTURE IMPROVEMENTS}

Future improvements intended for the system include modifications to the attachment of the drogue to the surface float to improve its performance and reliability in rougher seas. We plan to minimize the size and weight of the drifter by using GPS and data radio manufacturers' boards rather than entire off the shelf units and reduce the battery requirements by increasing the functionality of the micro-controller to include power management. By simplifying the float design, we could reduce the cost and speed up assembly while making it more robust for easier deployment and recovery. The tracking software can be improved by including a drifter name or number in addition to the icon on the real-time GIS display, which would improve identification of the drifters on the computer screen during tracking operations. 


\section{CONCLUSIONS}

The drifters and tracking system provided us with an extremely valuable new capability that enabled us to gain insight into the transport of coral larvae spawned off west Maui, Hawaii. Building on the experience gained through this experiment, we will be able to further improve the system and provide the USGS with an even better system to track the dispersal and fate not only of larvae, but also of other substances transported in the water column, such as sediment, nutrients, or contaminants. These data provide us with a much clearer picture of the nature of and controls on flow in the study area. A number of interesting phenomena were observed that indicate the complexity of coastal circulation in the channels between the islands of Maui, Lanai and Molokai.

\section{ACKNOWLEDGEMENTS}

This work was carried out as part of the USGS's Coral Reef Project as part of an effort in the U.S. and its trust territories to better understand the affect of geologic processes on coral reef systems. Project Chief Michael Field deserves thanks for providing us with the patience, opportunity, and support to carry out this experiment. Craig Okuda (MBARI) deserves special thanks for creating the circuit board layout \& design and numerous invaluable design suggestions. We would like to thank Joe Reich, the captain of the $R / V$ Alyce $C$., for his superb work during the long days chasing down the drifters in rough seas between the islands. We would also like to thank Ann Gibbs (USGS) and Joshua Logan (USGS), who contributed numerous excellent suggestions and a timely review of our work.

\section{LITERATURE CITED}

Storlazzi, C.D. and Jaffe, B.E., 2003. "Coastal Circulation and Sediment Dynamics along West Maui, Hawaii, PART I: Long-term measurements of currents, temperature, salinity and turbidity off Kahana, West Maui: 2001-2003." U.S. Geological Survey Open-File Report 03-482, 28 p. [ http://pubs.usgs.gov/of/2003/of03-482/ ]

Storlazzi, C.D., Logan, J.B., McManus, M.A., and McLaughlin, B.E., 2003. "Coastal Circulation and Sediment Dynamics along West Maui, Hawaii, PART II: Hydrographic Survey Cruises A-3-03-HW and A-4-03-HW Report on the spatial structure of currents, temperature, salinity and turbidity along Western Maui." U.S. Geological Survey Open-File Report 03-430, 50 p. [ http://pubs.usgs.gov/of/2003/of03-430/ ] 


\section{APPENDIX 1}

\section{Micro Controller Bill of Materials}

USGS DRIFTER Revised: Monday, May 12, 2003

Revision:

Bill Of Materials $\quad$ May 14,2003 9:26:50

\begin{tabular}{|c|c|c|c|c|c|}
\hline Item & Qty & Reference & Part & Vendor & cat number \\
\hline 1 & 6 & $\mathrm{C} 1, \mathrm{C} 2, \mathrm{C} 4, \mathrm{C} 5, \mathrm{C} 6, \mathrm{C} 9$ & 0.1 & digikey & PCC1853CT-ND \\
\hline 2 & 1 & C3 & .1uf & digikey & PCC1853CT-ND \\
\hline 3 & 2 & $\mathrm{C} 8, \mathrm{C} 7$ & $18 \mathrm{pf}$ & digikey & PCC180CNCT-ND \\
\hline 4 & 1 & $\mathrm{C} 10$ & 100uf & digikey & P11307CT-ND \\
\hline 5 & 1 & $\mathrm{D} 1$ & RED LED & digikey & 67-1612-ND \\
\hline 6 & 1 & $\mathrm{D} 2$ & 1N4001 Diode & digikey & DL4001DICT-ND \\
\hline 7 & 1 & $\mathrm{~J} 1$ & DB9M 90 deg pcb mount & digikey & A2096-ND \\
\hline 8 & 1 & $\mathrm{~J} 2$ & DB9F 90 deg pcb mount & digikey & A2100-ND \\
\hline 9 & 2 & $\mathrm{~J} 4, \mathrm{~J} 3$ & HEADER 5 & digikey & WM4003-ND \\
\hline 10 & 1 & R1 & $5.6 \mathrm{k} .1 \mathrm{w}$ & digikey & RR08P5.6KBCT-ND \\
\hline 11 & 1 & $\mathrm{R} 2$ & $500.1 w$ & digikey & P499CCT-ND \\
\hline 12 & 4 & $\mathrm{R} 3, \mathrm{R} 4, \mathrm{R} 5, \mathrm{R} 6$ & $100 \mathrm{~K} .1 \mathrm{w}$ & digikey & P100KCCT-ND \\
\hline 13 & 1 & s1 & SW DIP-4 & digikey & CT2094MS-ND \\
\hline 14 & 1 & U1 & MAX3232 296-13099-1-ND & digikey & 296-13099-1-ND \\
\hline 15 & 1 & $\mathrm{U} 2$ & PIC16F628 18 pin DIP & digikey & PIC16F628-20/P-ND \\
\hline 16 & 1 & U3 & LM7803 DC/DC 3.3v & digikey & 78ST133HC-ND \\
\hline 17 & 1 & Y1 & $20 \mathrm{mhz} 18 \mathrm{pf}$ load & digikey & 300-6003-ND \\
\hline & 1 & & 18 pin socket, DIP .300 & digikey & A403AE-ND \\
\hline
\end{tabular}




\section{APPENDIX 2}

\section{Power Budget Calculations}

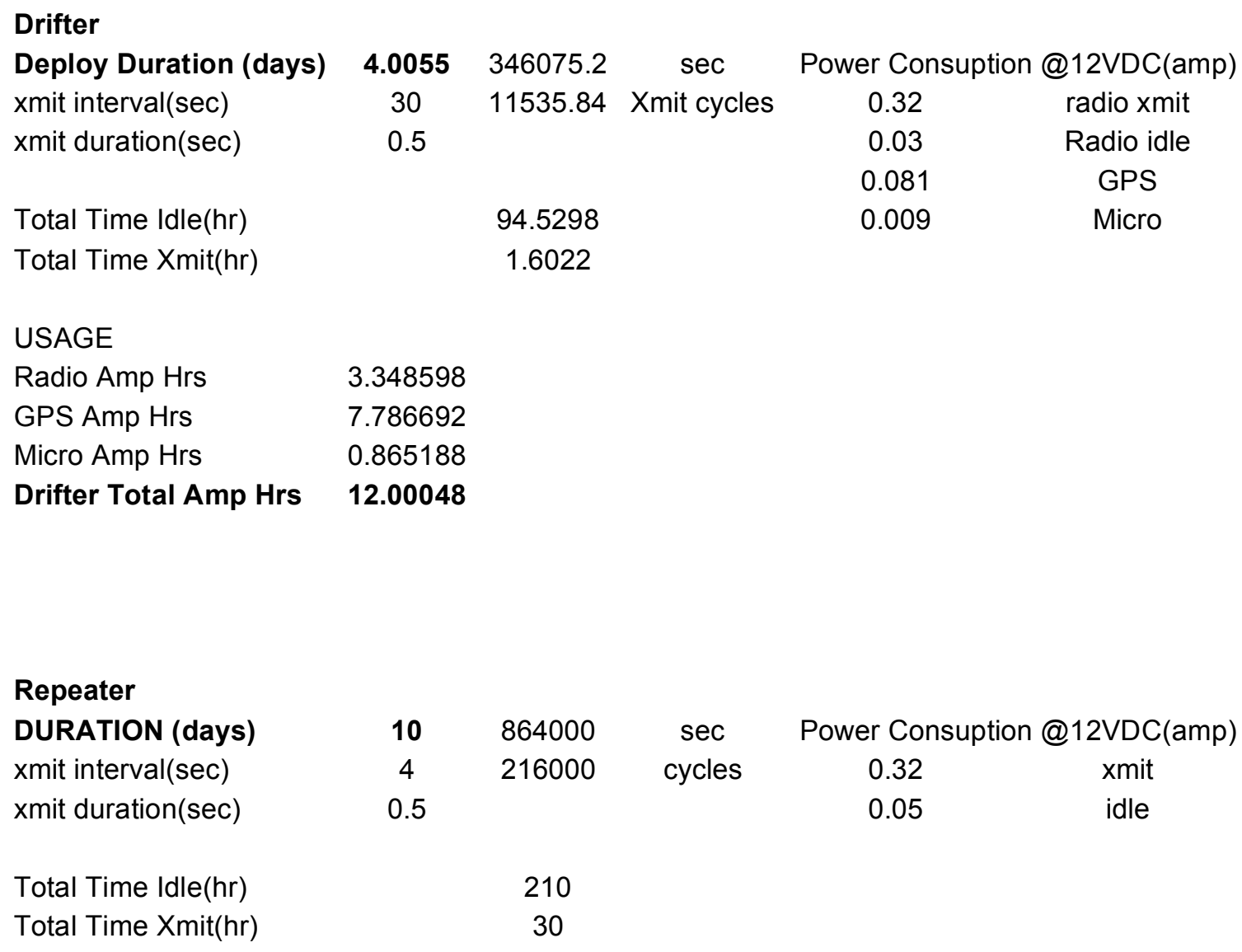

RPTR Total Amp Hrs $\quad 20.1$ 